\title{
Promestriene Affects GREB1 Expression in Estrogen Sensitive Breast Cancer Cells
}

\author{
Alvin J. O. Almodovar1', Xiang Zhu1, Sally A. Litherland1', David A. Decker1,2* \\ ${ }^{1}$ Florida Hospital Cancer Institute, Research \& Development Division, Orlando, FL, USA \\ ${ }^{2}$ University of Central Florida, College of Medicine, Orlando, FL, USA \\ Email: ${ }^{*}$ dadeckermd@aol.com
}

Received 22 April 2015; accepted 21 August 2015; published 24 August 2015

Copyright (C) 2015 by authors and Scientific Research Publishing Inc.

This work is licensed under the Creative Commons Attribution International License (CC BY). http://creativecommons.org/licenses/by/4.0/

(c) () Dpen Access

\begin{abstract}
Promestriene (3-propyl ethyl, 17B-methyl estradiol) is a synthetic estrogen analogue with reported minimal systemic absorption which has been suggested for topical treatment of vaginal atrophy. Promestriene's ability to stimulate proliferation and estrogen responsive gene expression was analyzed in estrogen receptor (ER+) positive breast cancer cell lines MCF-7, T-47D, and BT-474 using CFSE flow cytometric analysis, and quantitative RT-PCR analysis of GREB1 RNA expression, an estrogen responsive gene involved in estrogen receptor alpha expression. In estrogen replete conditions, Promestriene did not stimulate proliferation even at high concentrations $(100,000 \mathrm{pg} / \mathrm{ml})$. However, anti-estradiol depletion allowed low dose Promestriene $(2-10 \mathrm{pg} / \mathrm{ml})$ to stimulate GREB1 expression in all three cell lines at levels equal to that induced by estradiol (BT-474) or significantly higher than estradiol (MCF7 and T-47D). These findings suggest that Promestriene has the potential to support estrogen like cell signaling, a possible contraindication for use in treatment of vaginal atrophy associated with breast cancer aromatase inhibitor therapy.
\end{abstract}

\section{Keywords}

Breast Cancer, Survivor, Estrogen Receptor Positive, Hormone Therapy, Side Effects, Promestriene

\section{Introduction}

The National Cancer Institute of the National Institutes of Health 2015 report estimates life time risk for breast cancer for women in the United States at $12.3 \%$ [1]. The majority of breast cancer cases (70\% - 80\%) in the United States are reported as being hormone receptor positive $(\mathrm{HR}+)$, meaning that they express estrogen receptors (ER) or progesterone receptors (PR) or both [1]. ER+ breast tumors have the potential for their growth to be

*Corresponding author.

How to cite this paper: Almodovar, A.J.O., Zhu, X., Litherland, S.A. and Decker, D.A. (2015) Promestriene Affects GREB1 Expression in Estrogen Sensitive Breast Cancer Cells. Journal of Cancer Therapy, 6, 767-772. 
enhanced by estrogen. Early in breast cancer oncology, the discovery of breast cancer growth stimulation through ovarian hormones indicated the expression of estrogen receptors (ER) by tumor cells as a target for directed anti-hormone therapies. Direct antagonists of the ER and indirect depletion of circulating sources of estrogen (oophorectomy and anti-aromatase inhibitor (AI) therapies) became strong therapies for controlling ER mediated tumor growth [2]. Numerous selective estrogen receptor modulator (SERM) therapies have been proposed and tested for use in blocking ER function in pre-menopausal women as single therapies or in combination with tamoxifen with mixed success [1]-[5]. In post-menopausal and oophorectomized women blockade of adipose production of estrogen from androgens is most often accomplished using long term adjuvant HT therapies [6]-[8]. A problem arising from chronic exposure to anti-hormone therapies is side effects of estrogen deprivation including symptoms similar to those seen in menopausal women such as thinning and shrinking of vaginal and breast tissues, vaginal dryness, soreness, painful intercourse and urinary incontinence [6]-[8]. Topical application of Promestriene has been suggested as a possible treatment for reducing such symptoms.

Promestriene (3-propyl ethyl, 17B-methyl estradiol) is a synthetic estrogen analog that has been reported to significantly improve the symptoms of vaginal atrophy caused by estrogen deprivation in topical application [6] [7]. Promestriene has been studied and used in Europe, Asia, and South America to treat symptoms such as thinning and shrinking of tissue, vaginal dryness, soreness, painful intercourse and urinary incontinence [6]-[8]. Though topical application of Promestriene shows some absorption at the very beginning of treatment when the vaginal mucosa is thin, this minimal uptake is not observed after vaginal lining conditioning with chronic treatment [8]. Promestriene trials in Europe and India have demonstrated significant improvement in the symptoms of vaginal atrophy symptoms with little change in serum estradiol, FSH or LH levels [6] [7].

Promestriene's potential for treating vaginal atrophy symptoms associated with aromatase inhibitor treatment would be precluded if its minimal absorption leads to estrogen-like effects on cell proliferation and estrogenresponsive gene expression [8] [9]. The concern with absorbed vaginal estrogens or estrogen analogs is that they activate occult sites of residual breast cancer or negate the tumor suppressive effects of aromatase inhibitor adjuvant therapy [9].

Low dose vaginal estrogen treatments in postmenopausal breast cancer survivors demonstrated low levels of absorption in serum analyzed by ultra-sensitive GC or LC/MS/MS or immunoradio analyses [10] [11]. Most treatment trials with Promestriene were done before these sensitive assays were routinely used for clinical analysis [11]. It is possible that lower but biologically significant Promestriene absorption may have been missed in these trials. In this study, we tested Promestriene for its effects on ER+ breast cancer cell lines to determine if it has estrogen-like activity capable of promoting cancer cell proliferation and estrogen-responsive gene expression.

Estrogen-responsive gene expression was tested using ERalpha and GREB1, two genes known to be activated through estrogen-induced expression and using an epigenetic modification, histone acetylation [12] [13]. ERalpha is the gene encoding the estrogen-responsive subunit of the estrogen receptor itself. GREB1 is the most ER interactive factor induced by estradiol, the predominant form of estrogen found in serum [12]. GREB1 is one of the highest gene expression responses seen in estrogen-induction and has been found to support both estradiol induced ERalpha gene expression and ER function in MCF7 breast cancer cells [13]-[15]. The action of GREB1 in ERalpha expression requires direct chromatin binding at sites in the ERalpha gene locus that overlap with binding of P300/CBP histone acetylase, suggesting it is supporting histone acetylation modification involved in ERalpha gene regulation [13] [16]. GREB1 activity has been shown to be required for growth of ER+ breast cancer cells in vitro [12] [17] and its expression changed with anti-estrogen treatments [12].

\section{Methods and Materials}

Estrogen responsive ATCC ER+ breast cancer cell lines MCF-7 (ATCC HTB-22, VA), T-47D (ATCC HTB133, VA), and BT-474 (ATCC HTB-20, VA) were obtained directly from the American Type Culture Collection (ATCC) and used for in vitro dose-dependent, estrogen-like functional responses to Promestriene (PR, Santa Cruz Biotechnology, TX) in both estrogen-rich and estrogen-deprived conditions. As assay controls, cultures were treated in parallel with Fulvestrant (FR) (Sigma-Aldrich, MO), Testosterone (TE) (Sigma-Aldrich, MO), Progesterone (PE) (Sigma-Aldrich, MO) and Estradiol (E2) (Sigma-Aldrich, MO). All cultures were run in triplicate for each analysis run and the complete analysis was repeated twice for statistical comparison.

All cultures were grown to quiescence in phenol-free RPMI medium (ATCC 30-2602, Manassas, VA) supplemented with 10\% fetal calf serum (Cellgro/MediaTech, Manassas, VA) and insulin (Sigma-Aldrich, St Louis, 
$\mathrm{MO}$ ). To induce estrogen deprivation, cultures were then held 3 days at $37 \mathrm{C} / 5 \% \mathrm{CO}_{2}$ in the same media pretreated and continuously treated with anti-estrogen specific antibodies (Millipore, Billerica, MA) to sequester estrogen from the culture. Samples were split equally into 12-well cell culture plates for growth and use in RNA and flow cytometry analyzes. Cell lines were treated with each respective test stimulant at $0,2,7,10$ \& 50 $\mathrm{pmol} / \mathrm{L}$ concentration for both estrogen replete cultures and estrogen depleted cultures. The cultures were allowed to reach confluence (approximately 72 hours) and then trypsinized and split into fresh 12-well cultures for an additional 24 to $48 \mathrm{hr}$ in culture for proliferation and gene expression analysis.

Dose dependent estrogen-like proliferation responses in the cell lines were measured using flow cytometric analysis of CSFE (Life Technologies, Grand Island, NY) mitotic fluorescent dye dilution analyzed with BD Accuri flow cytometer (BD Biosciences, San Jose, CA). For the flow cytometry analysis, the data was collected using the BD Accuri C6 software (BD Biosciences, Hercules, CA) and processed using Kaluza Flow Analysis Software (Beckman-Coulter, Miami, FL). Data was compared as percentage of cells dividing compared to quiescent cells using linear regression over treatment concentrations for each cell line using Prism 6 (GraphPad Software, La Jolla, CA) and STATA IC12 (Stata Corp, College Station, TX) statistical software programs.

Estrogen-induced gene expression was measured using GREB1 RNA expression in real time quantitative RT-PCR analysis using TaqMan (Life Technologies). For real time PCR GREB1 expression assay (Hs00536403_ $\mathrm{m} 1$ ), the data was collected using BioRad Mini Opticon 3 software (BioRad, Hercules, $\mathrm{CA}$ ) and reported as $\Delta \Delta \mathrm{Ct}$ $=(G A P D H \Delta \mathrm{Ct})-(G R E B 1 \Delta \mathrm{Ct})$. Data for each culture treatment were analyzed using linear regression analysis and compared using multi-factorial (ANOVA) or pair-wise analyses to determine the significance of estrogen-like responses relative to the estradiol and untreated controls using GraphPad Prism 6 Software and STATA IC12 Software. Results were considered significant at $\mathrm{p}=0.05$.

\section{Results}

In estrogen sufficient cultures, Promestriene exhibited no cell proliferative properties on MCF-7, BT-474, or T47-D tumor cells, even at very high concentrations (Figure 1). However in estrogen deprivation conditions, low dose Promestriene ( $2-10 \mathrm{pg} / \mathrm{ml}$ ) stimulated GREB1 expression in all cell lines tested to levels equal to or greater than estrogen (Figure 2). In both estrogen replete and depleted cultures of MCF7 cells, $2 \mathrm{pg} / \mathrm{ml}$ Promestriene stimulated GREB1 expression significantly greater than that seen with estradiol ( $\mathrm{p}<0.0001$; Figure 2(a)). For BT-474 cells, there was no significant difference in the GREB1 expression stimulated by $2 \mathrm{pg} / \mathrm{ml}$ Promestriene compared to that induced by estradiol in either estrogen-replete or depleted conditions (Figure 2(b)).

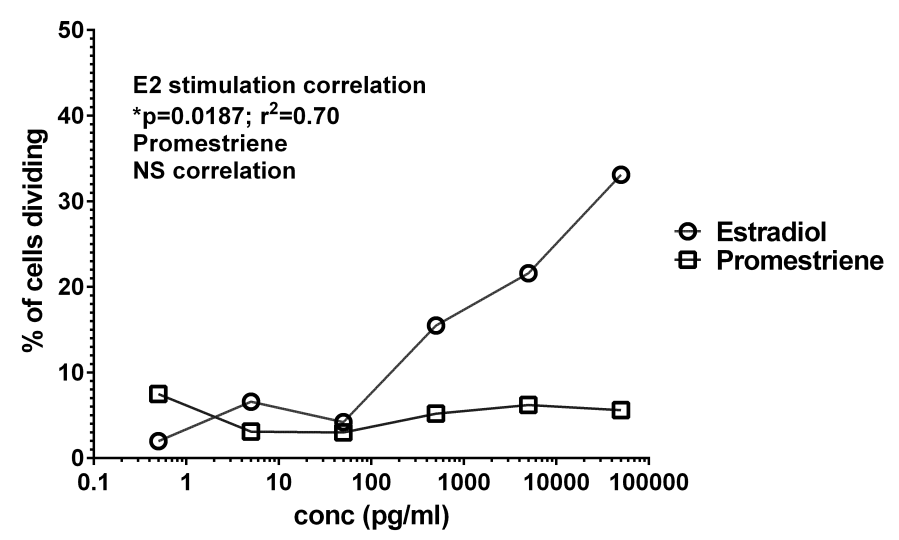

Figure 1. MCF7 ER+ Breast Cancer Cells are Unresponsive to Promestriene in Estrogen Rich Medium. MCF7 cells were grown to near-confluence and cells collected by trypsin digest. Duplicate cultures labeled with CSFE dye and then re-fed with medium supplemented with increasing doses 0 to $100,000 \mathrm{pg} / \mathrm{ml}$ ) of either estradiol (E2) or Promestriene (PR). Each treatment was run in triplicate and held for $24 \mathrm{hr}$ at $37 \mathrm{C} / 5 \% \mathrm{CO}_{2}$ prior to analysis by flow cytometry. Graph depicts mean of replicate analyses. CFSE fluorescence decrease was compared at each dose tested and linear regression analysis was performed testing the correlation of response to dose for each treatment (E2 or PR). The growth response of MCF7 cells to estradiol stimulation was linearly correlative with dose, $p=0.0187, r^{2}=0.70$. There was no significant linear correlation of MCF7 cell growth seen with Promestriene. 


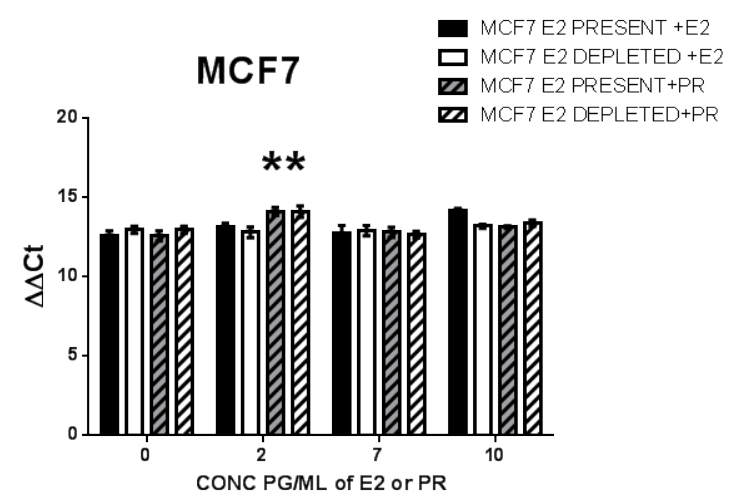

(a)

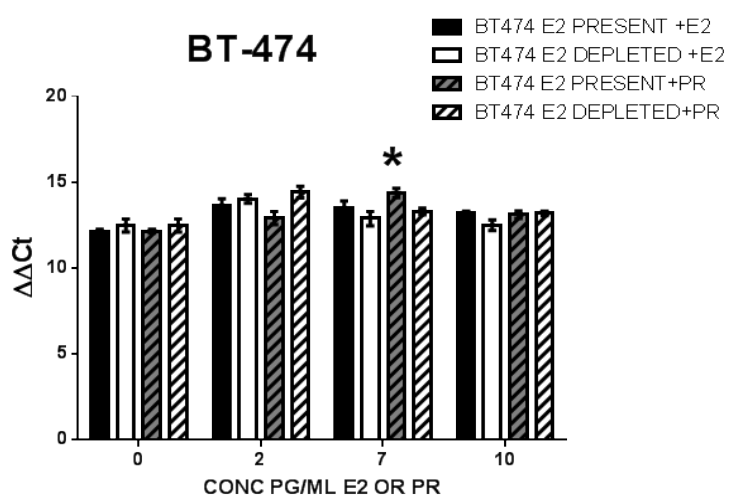

(b)

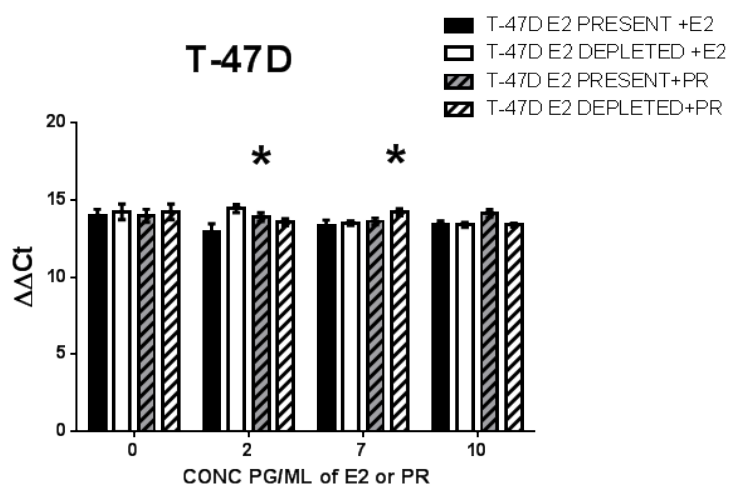

(c)

Figure 2. Promestriene Responsive GREB1 Expression under Estrogen Replete and Depleted Culture Conditions. Breast cancer cell lines MCF7, BT-474, and T-47D were grown with and without anti-estrogen antibodies in their medium until confluent. Cells were then collected by trypsin digest and labeled with CSFE dye before re-plating in the same media. The cell cultures were supplemented with low doses $(0-10 \mathrm{pg} / \mathrm{ml})$ of either Promestriene (PR) or estradiol (E2) for 3 days at $37 \mathrm{C} / 5 \% \mathrm{CO}_{2}$. Cells were collected by trypsin digest and extracted for total cellular RNA. Cellular RNA was subjected to RT-PCR and quantitatively analyzed using TaqMan primers specific for estrogen-responsive gene GREB1. Real time amplification quantitation was compared on the basis of $\triangle \Delta \mathrm{Ct}=(G A P D H \Delta \mathrm{Ct})-(G R E B 1 \triangle \mathrm{Ct})$. Mean and standard deviation of 6 replicates for each concentration and treatment are depicted. (a) In all cultures of MCF7 cells, 2 $\mathrm{pg} / \mathrm{ml}$ Promestriene promoted GREB1 mRNA expression significantly higher than estradiol ( $\mathrm{p}<$ 0.0001). (b) For BT-474 cells, Promestriene had effects on GREB1 mRNA expression equal to estradiol at $2 \mathrm{pg} / \mathrm{ml}$, but stimulated it significantly more than estradiol at $7 \mathrm{pg} / \mathrm{ml}$ in estrogen replete (present) cultures $(\mathrm{p}=0.0016)$. (c) D-47T cells responded to significantly to Promestriene compared to estradiol at $2 \mathrm{pg} / \mathrm{ml}$ in estradiol replete conditions $(\mathrm{p}=0.0027)$ and at $7 \mathrm{pg} / \mathrm{ml}$ in estrogen-depleted conditions ( $\mathrm{p}<0.0001)$. 
However, at $7 \mathrm{pg} / \mathrm{ml}$ Promestriene, BT-474 GREB1 mRNA expression was significantly stimulated in estradiol replete cultures compared to estradiol ( $\mathrm{p}=0.0016$; Figure 2(b)). For the T-47D cell line, $2 \mathrm{pg} / \mathrm{ml}$ Promestriene stimulation of GREB1 expression was significantly higher than that seen with estradiol in estrogen replete conditions ( $\mathrm{p}=0.0027$; Figure 2(c)), but not significantly different than estrogen in estrogen depleted conditions. However, at $7 \mathrm{pg} / \mathrm{ml}$ Promestriene stimulation, T-47D cells were significantly stimulated compared to estradiol in estradiol depleted conditions ( $\mathrm{p}<0.0001$; Figure 2(c)).

\section{Discussion}

Our studies findings are consistent with literature reports that unlike estradiol, Promestriene does not induce significant breast cancer cell growth at concentrations greater than $10 \mathrm{pg} / \mathrm{ml} \mathrm{(>10} \mathrm{pg/ml)} \mathrm{[7]} \mathrm{[8].} \mathrm{However,} \mathrm{Prome-}$ striene's ability to stimulate GREB1 expression in ER+ breast cancer cell lines at concentrations less than 10 $\mathrm{pg} / \mathrm{ml}$ gives evidence of its potential estrogenic effect in anti-estrogen treated breast cells. Promestriene provided stimulation in estrogen deprived conditions may be allowing cells to be activated through 1) an alternate signaling pathway [18], 2) flexibility in their receptor binding for analogs [12] [13] [18], and/or 3) increased expression or sensitivity of their estrogen receptors [12] [13] [18]. The role of chromatin epigenetic regulation of estrogen responsiveness has come to light as a potential treatment target for reversing hormone therapy resistant breast cancers, suggesting further study of the role GREB1 can play in this mechanism of gene activation in breast cancer is needed [19] [20]. These findings suggest that though the use of Promestriene to treat the symptoms associated with vaginal atrophy in postmenopausal women may be of clinical value, its potential as a treatment for aromatase inhibitor treatment-associated vaginal atrophy is questionable [9] [12].

\section{Conclusion}

The potential for Promestriene to stimulate estrogen-inducible gene expression in estrogen-deprived conditions, suggests caution should be used when prescribing it for breast cancer patients on aromatase inhibitor therapies. The mechanism of its estrogen-like functions for activating growth and gene expression in ER+ breast cancer cells warrants further investigation.

\section{Funding}

This work was supported by the generosity of the contributors to the Florida Hospital Foundation.

\section{Acknowledgements}

The authors also wish to thank James Rae, PhD and Georgine Lamvu, MD for expert advice, and Ms. Mimi Shao and Ms. Stephanie Dickstein for intellectual discussions and professional editorial review of the manuscript.

\section{References}

[1] Kohler, B.A., Sherman, R.L., Howlader, N., Jemal, A., Ryerson, A.B., Henry, K.A., Boscoe, F.P., Cronin, K.A., Lake, A., Noone, A.-M., Henley, S.J., Eherman, C.R., Anderson, R.N. and Penberthy, L. (2015) Annual Report to the Nation on the Status of Cancer, 1975-2011, Featuring Incidence of Breast Cancer Subtypes by Race/Ethnicity, Poverty, and State. Journal of the National Cancer Institute, Online 30 March 2015.

[2] Williams, C. and Lin, C.-Y. (2013) Oestrogen Receptors in Breast Cancer: Basic Mechanisms and Clinical Implications. Ecancermedicalscience, 7, 370-382.

[3] Munster, P.N., Thurn, K.T., Thomas, S., Raha, P., Lacevic, M., Miller, A., Melisko, M., Ismail-Khan, R., Rugo, H., Moasser, M. and Minton, S.E. (2011) A Phase II Study of the Histone Deacetylase Inhibitor Vorinstat Combined with Tamoxifen for the Treatment of Patients with Hormone Therapy-Resistant Breast Cancer. British Journal of Cancer, 104, 1828-1835. http://dx.doi.org/10.1038/bjc.2011.156

[4] Shen, C., Huang, Y., Liu, Y., Wang, G., Zhao, Y., Wang, Z., Ten, M., Wang, Y., Flockhart, D.A., Skaar, T.C., Yan, P., Nephew, K.P., Huang, T.H.M. and Li, L. (2011) A Modulated Empirical Bayes Model for Identifying Topological and Temporal Estrogen Receptor Alpha Regulatory Networks in Breast Cancer. BMC Systems Biology, 5, 67-83. http://dx.doi.org/10.1186/1752-0509-5-67

[5] Kubo, M., Kanaya, N., Petrossian, K., Ye, J., Warden, C., Liu, Z., Nishimura, R., Osako, T., Okido, M., Shimada, K., Takahashi, M., Chu, P., Yuan, Y.-C. and Chen, S. (2013) Inhibition of the Proliferation of Acquired Aromatase Inhibitor- 
Resistant Breast Cancer Cells by Histone Deacetylase Inhibitor LBH589 (Panobinostat). Breast Cancer Research and Treatment, 137, 93-107. http://dx.doi.org/10.1007/s10549-012-2332-x

[6] Del Pup, L. (2012) Management of Vaginal Dryness and Dyspareunia in Estrogen Sensitive Cancer Patients. Gynecological Endocrinology, 28, 740-745. http://dx.doi.org/10.3109/09513590.2011.652717

[7] Santos, I. and Clissold, S. (2010) Urogenital Disorders Associated with Estrogen Deficiency: The Role of Promestriene as Topical Oestrogen Therapy. Gynecological Endocrinology, 26, 644-651. http://dx.doi.org/10.3109/09513591003767948

[8] Wolff, J.-P., Cachelou, R. and Gueritee, N. (1982) Absence of Systemic Hormonal Effects in an Oestradiol Diether Topically Active on the Vaginal Mucosa. Maturitas, 4, 239-246. http://dx.doi.org/10.1016/0378-5122(82)90054-8

[9] Howell, A., Clarke, R.B., Evans, G., Bundred, N., Cuzick, J., Santen, R. and Allred, C. (2007) Estrogen Deprivation for Breast Cancer Prevention. Recent Results in Cancer Research, 174, 151-167. http://dx.doi.org/10.1007/978-3-540-37696-5_13

[10] Wills, S., Ravipati, A., Venuturumilli, P., Kesge, C., Folkerd, E., Dowsett, M., Hayes, D.F. and Decker, D.A. (2012) Effects of Vaginal Estrogens on Serum Estradiol Levels in Postmenopausal Breast Cancer Survivors and Women at Risk of Breast Cancer Taking an Aromatase Inhibitor or a Selective Estrogen Receptor Modulator. Journal of Oncology Practice, 11, 144-148. http://dx.doi.org/10.1200/JOP.2011.000352

[11] Fiers, T., Casetta, B., Bernaert, B., Vandersypt, E., Debock, M. and Kaufman, J.M. (2012) Development of a Highly Sensitive Method for the Quantification of Estrone and Estradiol in Serum by Liquid Chromatography Tandem Mass Spectrometry without Derivatization. Journal of Chromatography B, 893-894, 57-62. http://dx.doi.org/10.1016/j.jchromb.2012.02.034

[12] Rae, J.M., Johnson, M.D., Scheys, J.O., Cordero, K.E., Larios, J.M. and Lippman, M.E. (2005) GREB1 Is a Critical Regulator of Hormone Dependent Breast Cancer Growth. Breast Cancer Research and Treatment, 92, 141-149. http://dx.doi.org/10.1007/s10549-005-1483-4

[13] Mohammed, H., D’Santos, C., Serandour, A.A., Ali, H.R., Brown, G.D., Atkins, A., Rueda, O.M., Holmes, K.A., Theodorou, V., Robinson, J.L.L., Zwart, W., Saadi, A., Ross-Innes, C.S., Chin, S.-F., Menon, S., Stingl, J., Palmieri, C., Caldas, C. and Carroll, J.S. (2013) Endogenous Purification Reveals GREB1 as a Key Estrogen Receptor Regulatory Factor. Cell Reports, 3, 342-349. http://dx.doi.org/10.1016/j.celrep.2013.01.010

[14] Ghosh, M.G., Thompson, D.A. and Weigel, R.J. (2000) PDZK1 and GREB1 Are Estrogen-Regulated Genes Expressed in Hormone-Responsive Breast Cancer. Cancer Research, 60, 6367-6375.

[15] Dunbier, A.K., Anderson, H., Ghazoui, Z., Folkerd, E.J., A’hern, R., Crowder, R.J., Hoog, J., Smith, I.E., Osin, P., Nerurkar, A., Parker, J.S., Perou, C.M., Ellis, M.J. and Dowsett, M. (2010) Relationship between Plasma Estradiol Levels and Estrogen-Responsive Gene Expression in Estrogen Receptor-Positive Breast Cancer in Postmenopausal Women. Journal of Clinical Oncology, 28, 1161-1167. http://dx.doi.org/10.1200/JCO.2009.23.9616

[16] Zwart, W., Theodorou, V., Kok, M., Canisius, S., Linn, S. and Carroll, J.S. (2011) Oestrogen Receptor-Co-FactorChromatin Specificity in the Transcriptional Regulation of Breast Cancer. The EMBO Journal, 30, 4764-4776. http://dx.doi.org/10.1038/emboj.2011.368

[17] Liu, M., Wang, G., Gomez-Fernandez, C.R. and Guo, S. (2012) GREB1 Functions as a Growth Promoter and Is Modulated by IL6/STAT3 in Breast Cancer. PLoS ONE, 7, e46410. http://dx.doi.org/10.1371/journal.pone.0046410

[18] Englert, N.A., Spink, B.C. and Spink, D.C. (2011) Persistent and Non-Persistent Changes in Gene Expression Result from Long-Term Estrogen Exposure of MCF-7 Breast Cancer Cells. The Journal of Steroid Biochemistry and Molecular Biology, 123, 140-150. http://dx.doi.org/10.1016/j.jsbmb.2010.12.010

[19] Meng, Q., Chen, X., Sun, L., Zhao, C., Sui, G. and Cai, L. (2011) Carbamazepine Promotes Her-2 Protein Degradation in Breast Cancer Cells by Modulating HDAC6 Activity and Acetylation. Molecular and Cellular Biochemistry, 348, 165-171. http://dx.doi.org/10.1007/s11010-010-0651-y

[20] Yardley, D.A., Ismail-Khan, R.R., Melichar, B., Lichinitser, M., Munster, P.N., Klein, P.M., Cruickshank, S., Miller, K.D., Lee, M.J. and Trepel, J.B. (2013) Randomized Phase II, Double-Blind, Placebo-Controlled Study of Exemestane with or without Entinostat in Postmenopausal Women with Locally Recurrent or Metastatic Estrogen Receptor-Positive Breast Cancer Progressing on Treatment with a Nonsteroidal Aromatase Inhibitor. Journal of Clinical Oncology, 31, 2128-2135. http://dx.doi.org/10.1200/JCO.2012.43.7251 